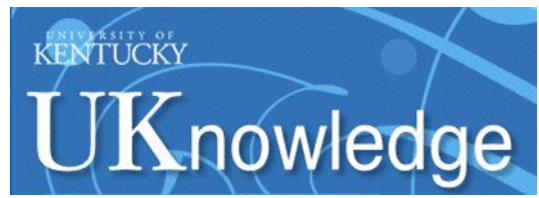

University of Kentucky UKnowledge

\title{
4-1982
}

\section{Hair as an Indicator of Excessive Aluminum Exposure}

Robert A. Yokel

University of Kentucky, ryokel@email.uky.edu

Right click to open a feedback form in a new tab to let us know how this document benefits you. Follow this and additional works at: https://uknowledge.uky.edu/ps_facpub

Part of the Pharmacy and Pharmaceutical Sciences Commons 


\section{Hair as an Indicator of Excessive Aluminum Exposure}

\section{Notes/Citation Information}

Published in Clinical Chemistry, v. 28, no. 4, p. 662-665.

(C) 1982 The American Association for Clinical Chemistry

RA Yokel, Hair as an indicator of excessive aluminum exposure. Clinical Chemistry, April 1982, v. 28, no. 4, p. 662-665. (reproduced with permission from the American Association for Clinical Chemistry). 


\title{
Hair as an Indicator of Excessive Aluminum Exposure
}

\author{
Robert A. Yokel
}

To determine if excessive systemic exposure to aluminum would be reflected in increased aluminum concentration in hair, rabbits were given a series of aluminum lactate injections. Hair was collected before the aluminum lactate administration from the site of injections and twice after the injections from this site as well as from an area adjoining the injection site. Aluminum was determined by flameless atomic absorption analysis of acid-digested samples. The concentration of aluminum in the hair increased after the injections in samples taken at both times from both sites. Considerable variability in hair aluminum was found before excessive exposure, as has been reported in humans, and in response to the exposure. The increase in hair aluminum did not correlate with the amount of hair produced. Nevertheless, because some subjects exposed to excessive aluminum showed a very large increase in hair aluminum, hair may be a useful indicator of aluminum body burden in such aluminum-induced conditions as dialysis encephalopathy.

Additional Keyphrases: atomic absorption spectroscopy dialysis encephalopathy - toxicology - trace elements Alzheimer's disease - rabbits - "normal" values

There is considerable interest and controversy concerning the proposed role of excessive aluminum exposure and accumulation as the cause of progressive, fatal encephalopathies. Following the observation that topical application of aluminum to the brain produces neurofibrillary tangles similar to those seen in presenile dementia of the Alzheimer's type (1), concentrations of aluminum in autopsy specimens of brain from victims of Alzheimer's disease were measured and found to be increased (2). It has been suggested that aluminum may cause Alzheimer's disease (2), but subsequent work has shed doubt on this suggestion (3). However, aluminum does appear to accumulate in the neurofibrillary tangles of Alzheimer's disease (4). Considerable evidence points to excessive aluminum consumption (via antacids) or exposure (via dialysis fluid) as the cause of a progressive fatal encephalopathy seen in chronic dialysis patients and patients with chronic renal failure who have not been dialyzed $(5,6)$. Greatly increased concentrations of aluminum in blood have been noted in these individuals.

Hair is frequently used to indicate excessive exposure to trace elements (7), but there are only a few reports of hair analysis for aluminum in people with neurological and behavioral disorders. Increased aluminum was found in hair of several 12- to 18-year-old boys with severe emotional problems (8). Hair of a two-year-old with severe emotional problems who resided near an aluminum processing plant was reported to have an increased aluminum concentration (8). During routine analysis of hair for trace-metal content, unexpectedly high concentrations of aluminum were found in the hair of patients with neurologic and other disorders (9). Dolomite was

College of Pharmacy and Graduate Center for Toxicology, 101 Pharmacy Bldg., University of Kentucky, Lexington, KY 405360053.

Received Nov. 24, 1981; accepted Jan. 27, 1982. thought to be the source of the aluminum in many of these cases.

These reports suggest that excessive aluminum exposure may be reflected in an increase in aluminum in hair. Because, to my knowledge, there are no published attempts to determine if an increase in the aluminum content of hair follows known (excessive) exposure, I conducted the present study. As I am unaware of published reports of aluminum hair concentration in the laboratory rabbit, I also analyzed in the present study a mixed sample of human hair, to facilitate comparison of results from this study with the numerous reports on aluminum content of human hair. The hair washing procedure used has been shown, among those tested, to least influence the content of copper, zinc, and magnesium in hair analyzed by atomic absorption spectroscopy (10). To determine whether the washing procedure affected the hair aluminum concentration, I compared this washing procedure with the procedure routinely used for the International Atomic Energy Agency (IAEA) coordinated research program (11).

\section{Materials and Methods}

Forty-eight adult female New Zealand White rabbits, weighing 1.5 to $4.2 \mathrm{~kg}$ at the beginning of the study, were used as subjects. For at least two weeks before and throughout the study, they were individually housed with unlimited access to Purina Rabbit Chow feed (found to contain about $1200 \mathrm{mg}$ of $\mathrm{Al}$ per kilogram) and water (Al content, $64 \mu \mathrm{g} / \mathrm{L}$ ).

At the beginning of the study, an area in the center of the back (approx. $8 \times 10 \mathrm{~cm}$ ) was shaved with a small animal clipper equipped with an angra blade (Oster Manufacturing Co., Milwaukee, WI 53217); this was the baseline hair sample (Sample 1). Twenty subcutaneous injections (five weekly for four weeks) were then given into random sites under this shaved area. Eight subjects received Al injections of either 0 , $25,50,100,200$, or $400 \mu \mathrm{mol} / \mathrm{kg}$ of body weight. Each injection was $0.5 \mathrm{~mL}$ of sterile water or aluminum lactate $(0.05,0.1,0.2$, 0.4 , or $0.8 \mathrm{~mol}$ of $\mathrm{Al}$ per liter) per kg of body weight. Five and nine weeks after the injections began, the previously shaved area was reshaved (Samples 2 and 4, respectively), and previously unshaved areas about $2-\mathrm{cm}$ wide on either side of the previously shaved areas were also shaved and combined (Samples 3 and 5, respectively). Thus, five hair samples were obtained from each subject.

After weighing each hair sample, approximately $100 \mathrm{mg}$ was placed in a preweighed 7-mL Teflon perfluoroalkoxy screwcap container (Tuf-Tainer ${ }^{\mathrm{Tm}}$; Pierce Chemical Co., Rockford, IL 61105). The samples were washed with consecutive 30-min washes of the following: $5 \mathrm{~mL}$ each of hexane (one wash), $95 \%$ ethanol (three washes), and de-ionized water (three washes) (10). The samples were vortex-mixed every $10 \mathrm{~min}$ during this procedure. After the samples were dried to constant weight at $70^{\circ} \mathrm{C}, 0.5 \mathrm{~mL}$ of acid mixture (nitric/perchloric/sulfuric, $392 / 98 / 10$ by vol) was added to each sample, which was digested at $70^{\circ} \mathrm{C}$ in the closed container. Double distilled $70 \%$ nitric and $70 \%$ perchloric acids (G. Frederick Smith Chemical Co., Columbus, $\mathrm{OH} 43223$ ) and reagent grade sulfuric acid (Fisher Scientific Co., Fair Lawn, NJ 07410) were used. The caps were then loosened and the containers placed in a glass desiccator that had a hole drilled in the side near the bottom. 
Table 1. Aluminum Concentration in Hair of Rabbits

\begin{tabular}{|c|c|c|c|c|c|}
\hline \multirow{3}{*}{$\begin{array}{l}\text { Aluminum } \\
\text { injected, } \\
\mu \mathrm{mol} / \mathrm{kg} \\
\text { per injection }\end{array}$} & \multicolumn{5}{|c|}{ Mean \pm SD (and range) } \\
\hline & \multirow{2}{*}{$\begin{array}{c}\text { Baselline AI } \\
\text { (before injection), } \\
\text { mg/kg }\end{array}$} & \multicolumn{4}{|c|}{$\%$ of baselline } \\
\hline & & Sample $2^{\circ}$ & Sample $3^{\circ}$ & Sample 4* & Sample $5^{\circ}$ \\
\hline 0 & $\begin{array}{l}1.16 \pm 0.70^{b} \\
(0.39-2.50)\end{array}$ & $\begin{array}{c}116 \pm 69 \\
(36-246)\end{array}$ & $\begin{array}{l}98 \pm 54 \\
(36-180)\end{array}$ & $\begin{array}{l}92 \pm 49 \\
(36-159)\end{array}$ & $\begin{array}{l}88 \pm 22 \\
(61-165)\end{array}$ \\
\hline 25 & $\begin{array}{l}0.84 \pm 0.45 \\
(0.36-1.82)\end{array}$ & $\begin{array}{r}224 \pm 223 \\
(15-716)\end{array}$ & $\begin{array}{r}135 \pm 108 \\
(25-338)\end{array}$ & $\begin{array}{r}148 \pm 143 \\
(38-451)\end{array}$ & $\begin{array}{c}129 \pm 78 \\
(37-257)\end{array}$ \\
\hline 50 & $\begin{array}{l}0.79 \pm 0.43 \\
(0.12-1.38)\end{array}$ & $\begin{array}{r}240 \pm 181 \\
(58-551)\end{array}$ & $\begin{array}{c}110 \pm 78 \\
(19-254)\end{array}$ & $\begin{array}{c}161 \pm 89 \\
(61-290)\end{array}$ & $\begin{array}{c}130 \pm 52 \\
(73-234)\end{array}$ \\
\hline 100 & $\begin{array}{l}0.90 \pm 0.36 \\
(0.46-1.58)\end{array}$ & $\begin{array}{r}759 \pm 1655 \\
(65-4843)\end{array}$ & $\begin{array}{l}91 \pm 39 \\
(34-143)\end{array}$ & $\begin{array}{l}88+41 \\
(38-175)\end{array}$ & $\begin{array}{c}135 \pm 82 \\
(41-265)\end{array}$ \\
\hline 200 & $\begin{array}{l}0.72 \pm 0.46 \\
(0.20-1.54)\end{array}$ & $\begin{array}{l}889 \pm 945 \\
(226-3072)\end{array}$ & $\begin{array}{r}249 \pm 155 \\
(98-567)\end{array}$ & $\begin{array}{l}230 \pm 131 \\
(105-441)\end{array}$ & $\begin{array}{c}188 \pm 93 \\
(98-356)\end{array}$ \\
\hline 400 & $\begin{array}{l}1.05 \pm 0.90 \\
(0.26-2.51)\end{array}$ & $\begin{array}{r}4432 \pm 9790 \\
(193-28526)\end{array}$ & $\begin{array}{r}532 \pm 646^{c} \\
(73-2067)\end{array}$ & $\begin{array}{r}3093 \pm 7769 \\
(56-22309)\end{array}$ & $\begin{array}{r}190 \pm 108 \\
(41-318)\end{array}$ \\
\hline
\end{tabular}

- Sample 2 = Hair sample obtained one week after completion of Al injections (five weeks after injections began) from the previously shaved area; Sample 3 = Hair sample obtained at same time as Sample 2 from a previously unshaved area on either side of Sample 2; Sample 4 = Hair sample obtained five weeks after completion of Al injections (nine weeks after injections began) from the previously shaved areas; Sample 5 = Hair sample obtained at same time as Sample 4 from a previously unshaved area on either side of Sample 4 . $^{b} n=8$ for each mean. $c$ Different from 0 Al injection group, $p<0.01$.

The desiccator was placed in an oven, and the nitric and perchloric acids were evaporated by gradually increasing the temperature to $160^{\circ} \mathrm{C}$. The evaporated acids were collected in a series of aqueous sodium hydroxide traps connected to the desiccator cover hose connector by glass tubing. A vacuum pump pulled air through the desiccator and traps. This system (details available upon request) avoided the potential dangers of evaporated acids, particularly the explosive perchlorate salts. The resulting sample was diluted to $1 \mathrm{~g}$ by addition of dilute nitric acid $(2 \mathrm{~mL} / \mathrm{L})$ to containers on an analytical balance. Samples with considerable $\mathrm{Al}$ required further dilution. Eighty-five percent of the aluminum standard added to hair samples before acid digestion was recovered in the final dilution. Containers receiving only the acid mixture were included with each group of samples to correct for Al contamination from the acids.

Al content was determined by quadruplicate injection of the sample (by Eppendorf pipette) into the HGA-500 furnace of an atomic absorption spectrophotometer (Model 460; Perkin-Elmer Corp., Norwalk, CT 06856). The HGA-500 was programmed as follows:

$\begin{array}{cccc}\text { Step } & \text { Temp },{ }^{\circ} \mathrm{C} & \text { Ramp time, } s & \text { Hold time, } s \\ 1 & 110 & 20 & 20 \\ 2 & 500 & 10 & 10 \\ 3 & 1400 & 20 & 20 \\ 4 & 2700 \text { (maximum } & 0 & 3\end{array}$

Peak height absorption was read at $396.2 \mathrm{~nm}$, which is less noisy than at $309.3 \mathrm{~nm}$ (12). Background absorbance is not a significant problem in the determination of aluminum in acid-digested samples at $396.2 \mathrm{~nm}$ as evidenced by $(a)$ the lack of difference between sample readings at $396.2 \mathrm{~nm}$ vs those at 309.3 minus $307 \mathrm{~nm}$ (background) and (b) the lack of background absorbance in samples analyzed at $396.2 \mathrm{~nm}$ with a deuterium lamp (communication from Alan King, PerkinElmer Technical Support Division, Cincinnati, $\mathrm{OH}$ ).

Considerable variability was found in the aluminum of baseline samples; therefore, the aluminum content of each hair sample obtained one and five weeks after the chronic aluminum exposure (five and nine weeks after the injections were begun) was determined as a percentage of baseline for that subject. The rate of growth of hair fibers can influence the amount of trace elements in hair (13) and, in turn, be affected by nutritional status, which can be influenced by trace-element status. Because some subjects in this study produced much less hair during and after injections than other subjects, the concentration of aluminum in the hair $(\mathrm{mg} / \mathrm{kg})$ was compared with the amount of hair produced $(\mathrm{g})$, to determine whether the increase in hair aluminum might be due to a change in the quantity of hair produced.

For comparison with reports of aluminum in human hair, one day's collection of hair clippings was obtained from a local barbershop and 10 samples of this well-mixed collection were analyzed by the above procedures. To compare the washing procedure used in the present study with that used in IAEA collaborative studies (11), we washed 10 of these human hair samples by the IAEA procedure - consecutive 10-min washes with acetone (once), de-ionized water (thrice), and acetone (once) - and analyzed as above. Unwashed hair samples were also digested and analyzed. The two washing procedures were further compared by washing duplicate samples from one rabbit, obtained from each of the five shavings described above.

Statistical significance for the rabbit samples was determined by analysis of variance and Duncan's multiple range test for variable data. Differences in the human hair samples washed by the two tested procedures were assessed by use of Student's $t$-test.

\section{Results}

Baseline hair aluminum concentration in rabbits averaged $0.91 \mathrm{mg} / \mathrm{kg}$ (mean of six values shown in Table 1). After 20 subcutaneous aluminum lactate injections into the back, there was a dose-dependent increase in hair aluminum concentration, as shown in Table 1 . The increase was in hair samples obtained from the region of the injections (Samples 2 and 4) and in those surrounding that region (Samples 3 and 5). Analysis of variance indicated that hair in Sample 3 showed a significant difference in aluminum concentration among the six exposure groups $(F=3.04, p<0.02)$. Duncan's multiple range test for variable data (14) indicated that rabbits re- 
ceiving $400 \mu \mathrm{mol} / \mathrm{kg}$ per injection had hair aluminum concentrations greater than the control group $(p<0.01)$.

Comparison of hair sample weights and their aluminum concentrations for all six aluminum injection levels showed no significant correlation ( $r=-0.11$ for Sample 2 and -0.18 for Sample 4). When correlation coefficients were determined between hair sample weight and aluminum concentration within each injection group, the correlation was significant $(r=-0.92, p<0.005)$ only for Sample 4 from those rabbits receiving $25 \mu \mathrm{mol}$ of $\mathrm{Al} / \mathrm{kg}$ per injection. The other $r$ values ranged from -0.63 to +0.65 .

The human hair samples washed by the hexane/ethanol/ water method resulted in aluminum concentrations $(14.71 \pm$ $1.82 \mathrm{mg} / \mathrm{kg}$, mean \pm SD) that were $81 \%$ of those obtained from samples washed by the acetone/water/acetone method (18.14 $\pm 1.62 \mathrm{mg} / \mathrm{kg})$, significantly different $(t=8.53, p<0.001)$. Unwashed human hair samples showed much more variability in $\mathrm{Al}$, averaging $29.10 \mathrm{mg} / \mathrm{kg}$. Aluminum concentration in the five hair samples analyzed from one rabbit were slightly lower (mean 94.5\%) for the hexane/ethanol/water wash than the acetone/water/acetone wash. This difference was not statistically significant.

\section{Discussion}

The use of hair as an indicator tissue would seem to offer some advantages over other tissues in documenting $(a)$ deficiency of a required nutrient, e.g., zinc, owing to malabsorption; (b) exposure to substances to which people are not normally exposed, e.g., phencyclidine; or (c) excessive exposure to potentially toxic substances, e.g., lead. Obtaining a hair sample is a relatively noninvasive technique compared with the methods for obtaining samples of body tissues or fluids. If the substance of interest is deposited in the hair, previous exposure can probably be determined at a much later date from a hair than a urine, fecal, or blood sample. However, before analysis of hair samples can be considered a valid indicator of previous exposure, it must be demonstrated that such analysis will reliably reflect previous exposure. There have been many reports of "normal" hair aluminum concentration $(11,15)$. Of the many methods available for quantitative analysis for aluminum, atomic absorption spectroscopy, neutron activation analysis, and inductively coupled plasma spectroscopy are probably the most sensitive and specific. Atomic absorption spectroscopy is the most widely available of these. The only previously reported studies of atomic absorption spectroscopy to analyze hair for aluminum $(16,17)$ found it a satisfactory method.

From the present study it appears that injections of aluminum lactate into rabbits resulted in increased hair aluminum concentration. These injections also resulted in greatly increased aluminum concentration in peripheral organs (unpublished results). The data in Table 1 show dose-dependent increases in average hair aluminum concentrations and a significant difference between Sample 2 from the 400 $\mu \mathrm{mol} / \mathrm{kg}$ injection group and the control group. This indicates that aluminum is deposited into growing hair during excessive systemic aluminum exposure.

Table 1 also shows that there is considerable variation in the aluminum concentration in hair of subjects not previously exposed to excessive aluminum. Similar large variations in hair aluminum have been reported among "normal" humans (range $<0.24-67.1 \mathrm{mg} / \mathrm{kg}$ for 194 people) (18), from proximal to distal segments of the same hair fiber, and from hair samples from various anatomical sites from the same subject (17). Therefore, it is not surprising to find that rabbits that are exposed to the same concentration of aluminum demonstrate variable uptake and storage of aluminum in hair. This variability does not seem to be a function of the amount of hair produced, no consistent correlation being observed between hair sample weights and aluminum concentration. What factors contribute to the variability of aluminum in hair have not been determined.

The trend toward higher concentrations of aluminum in samples obtained from previously unshaved areas one week after the end of the aluminum injections (Sample 3) compared with those five weeks after aluminum injections (Sample 5) may be due to the pattern of hair production and turnover in the young rabbit. In the young rabbit, hair grows diffusely over the trunk; therefore, after aluminum exposure, new hair would dilute the aluminum-containing older hair. The young rabbit may be a good model for hair growth and replacement studies in humans, who demonstrate a mosaic hair-replacement pattern in which hair is replaced irregularly, each follicle having its own hair growth and replacement cycle independent of adjacent hair follicles (20).

Numerous hair-washing methods have been used, to attempt to remove surface contamination without leaching the analyte from the sample. The hexane/ethanol/water wash was used in the present study because it reduced the concentration of copper, zinc, and magnesium in human hair less than did a detergent wash or an acetone/ether/detergent wash (10). No one has published a comparison of the effects of washing methods on aluminum hair content. Results from this study suggest that the acetone/water/acetone wash method used by IAEA collaborators would be preferable over the hexane/ ethanol/water wash in aluminum hair analysis, because it reduces the aluminum concentration in hair less and is much faster.

The values for human hair aluminum in the present study are higher than those found in "normal" populations in other areas (mg/kg hair): 6.5 for English samples, by atomic absorption spectroscopy (16); 3.7 for U.S., 8.8 for rural Japan, 11.9 for Hong Kong, and 13.6 for Tokyo samples, by neutron activation (11); and up to 10 for U.S. samples, by inductively coupled plasma spectroscopy (8). The lack of considerable variability among the 10 replicate determinations of human hair in the present study indicate that the methods used were reproducible. These results further indicate that the variability seen among the rabbit hair samples is, in fact, due to variation in the aluminum content.

The present study indicates that excessive systemic aluminum exposure may be reflected in increased hair aluminum concentration. It would be interesting to see if patients with Alzheimer's disease or those suffering from dialysis encephalopathy syndrome have increased hair aluminum concentration.

This work was supported by NIH grant 1 R02 MH 34188 and a grant from the University of Kentucky Research Foundation. I thank Marcia T. Willhite for her skilled assistance and Dr. William C. Lubawy for his helpful comments on the manuscript.

\section{References}

1. Klatzo, I., Wisniewski, H., and Streicher, E., Experimental production of neurofibrillary degeneration. J. Neuropathol. Exp. Neurol. 24, 187-199 (1965).

2. Crapper, D. R., Krishnan, S. S., and Dalton, A. J., Brain aluminum distribution in Alzheimer's disease and experimental neurofibrillary degeneration. Science 180, 511-513 (1973).

3. McDermott, J. R., Smith, A. I., Iqbal, K., and Wisniewski, H. M., Brain aluminum in aging and Alzheimer disease. Neurology 29, 809-814 (1979).

4. Perl, D. P., and Brody, A. R., Alzheimer's disease: X-ray spectrometric evidence of aluminum accumulation in neurofibrillary tangle-bearing neurons. Science 208, 297-299 (1980).

5. Alfrey, A. C., Dialysis encephalopathy syndrome. Annu. Rev. Med. 29, 93-98 (1978).

6. Nathan, E., and Pedersen, S. E., Dialysis encephalopathy in a 
non-dialyzed uraemic boy treated with aluminum hydroxide orally. Acta Paediatr. Scand. 69, 793-796 (1980).

7. Maugh, T. H., Hair: A diagnostic tool to complement blood serum and urine. Science 202, 1271-1273 (1978).

8. Rees, E. L., Aluminum toxicity as indicated by hair analysis. $J$. Orthomol. Psychiatr. 8, 37-43 (1979).

9. Roberts, H. J., Dolomite as a source of toxic metals. N. Engl. J. Med. 304, 423 (1981).

10. Assarian, M. S., and Oberleas, D., Effect of washing procedures on trace-element content of hair. Clin. Chem. 23, 1771-1772 (1977).

11. International Atomic Energy Agency, Activation analysis of hair as an indicator of contamination of man by environmental trace element pollutants. Report IAEA/RL/50, Vienna, October 1978.

12. Krishnan, S. S., Gillespie, K. A., and Crapper, D. R., Determination of aluminum in biological material by atomic absorption spectrophotometry. Anal. Chem. 44, 1469-1470 (1972).

13. Bradfield, R. B., and Hambidge, K. M., Problems with hair zinc as an indicator of body zinc status. Lancet i, 363 (1980).
14. Helwig, J. T., and Council, K. A., Eds., SAS User's Guide, SAS Institute, Raleigh, NC, 1979.

15. Sorenson, J. R. J., Campbell, I. R., Tepper, L. B., and Lingg, R. D., Aluminum in the environment and human health. Environ. Health Perspect. 8, 3-95 (1974).

16. Alder, J. F., Samuel, A. J., and West, T. S., The single element determination of trace metals in hair by carbon-furnace atomic absorption spectrometry. Anal. Chim. Acta 87, 313-321 (1976).

17. Alder, J. F., Samuel, A. J., and West, T. S., The anatomical and longitudinal variation of trace element concentration in human hair. Anal. Chim. Acta 92, 217-221 (1977).

18. Imahori, A., Fukushima, I., Shiobara, S., et al., Multielement neutron activation analysis of human scalp hair. A local population survey in the Tokyo metropolitan area. J. Radioanal. Chem. 52, 167-180 (1979).

19. Whiteley, H. J., and Ghadially, F. N., Hair replacement in the domestic rabbit. J. Anat. 88, 13-18 (1954).

20. Ryder, M. L., Hair. Studies in Biology, No. 41, Camelot Press, London, 1973, 58 pp. 